\title{
Improvements of a Hard-Wall Closed Test-Section of a Subsonic Wind Tunnel for Aeroacoustic Testing
}

\author{
Odenir de Almeida \\ Experimental Aerodynamics Research Center (CPAERO), Federal University of Uberlandia (UFU), Uberlandia, \\ Brazil. E-mail: odenir.almeida@ufu.br
}

\author{
Fernando M. Catalano and Lourenco Tercio Pereira \\ São Carlos School of Engineering, University of São Paulo (USP), São Carlos, Brazil.
}

\begin{abstract}
(Received 25 April 2021; accepted 17 July 2021)
For achieving accurate aeroacoustic measurements to the aircraft industry, a low-speed wind tunnel, primarily designed for aerodynamic testing, is modified to provide lower background noise environment. Based on data from single microphone at different wind tunnel locations and microphone phased-array measurements inside the test-section, the main noise sources are identified and feasible alternatives are implemented for reducing the background noise such as new acoustically treated corner-vanes and sidewall lining located upstream the drive system. The acoustically transparent concept for the test-section is also investigated showing promising results for further improvements in the wind tunnel. Results are presented for sound pressure levels from single microphone measurements at different locations in the wind tunnel as well as from the beamforming array inside the testsection. Background noise measurements before and after improvements confirm that the ability of performing aeroacoustic tests has significantly increased with noise reduction of $5 \mathrm{~dB}$ inside the test-section.
\end{abstract}

\section{INTRODUCTION}

The growing demand of the air-transport industry for low noise aircraft has challenged universities and research centers around the world to either improve or design new experimental facilities for aeroacoustic measurements. It is well known that aeroacoustic experiments cannot be pursued in standard subsonic wind tunnels, mainly due to high levels of background noise in the hard-wall and closed test-section. For this reason, in the last decades, many wind tunnels (WT) have passed through upgrades to perform aeroacoustic measurements as well as traditional aerodynamic flow evaluation mainly in the aeronautic branch. In fact, the aviation industry demands high aerodynamics performance and the ability for measuring and identify noise sources. Most of those facilities are large and relatively old. Therefore, an upgrade was more adequate. Also, it is worth noting that some of the wind tunnel circuit's noise sources are difficult to cure without radical modifications. The design process of an aeroacoustic wind tunnel is very complex since a good compromise between acoustic and aerodynamic characteristics must be achieved. ${ }^{1}$

When dealing with measurements in a wind tunnel, it is always too hard to match aerodynamics with aeroacoustics, mainly due to physical interferences such as hard-walls and its boundary layers, jet shear layers, propagation of fan noise, jet-collector impingement and consequently unsteadiness of flow motion, among other issues. In the aeroacoustics side, there is also the need for reducing background noise to simulate farfield environments as truly as possible. ${ }^{2}$ Although these are recurring problems into this field, it is possible to verify the existence of both open and close test-sections for achieving aeroacoustic experiments with terrestrial and aerial vehi- cles. The description of the Florida State Aeroacoustic Tunnel (FSAT), which is an open-circuit anechoic wind tunnel designed for low subsonic aerodynamic noise studies is provided by. ${ }^{3}$ The work of ${ }^{4}$ presents a wind tunnel configuration which is closed aerodynamically and open acoustically by means of using non-hard-wall material such as Kevlar. The works of ${ }^{5,6}$ discuss and compare many open-jet facilities for aeroacoustic measurements and summarize the challenges found in closedsection wind tunnels.

Notwithstanding, closed wind tunnel test sections have been applied for aeroacoustic measurements in the last decade, despite the fact of higher noise levels and reverberation in the test-section. Early works such as ${ }^{7}$ investigated a $1 / 4$ scale model of the A340 main landing gear in a closed test-section through phased array microphone measurements. Conventional beamforming and deconvolution techniques were applied to dereverberate noise levels from microphone array measurements in hard-wall closed-section wind tunnels by. ${ }^{8}$ The authors ${ }^{9}$ expanded their measurements and control of aircraft landing gear broadband noise. At the time, the results were complemented with an open-jet aeroacoustic facility using farfield microphones to verify the wind tunnel test results showing reasonable accuracy in mid- and high-frequency range. The authors ${ }^{10}$ proposed aeroacoustic imaging in a closed-section wind tunnel for studying a modern commercial transport aircraft in China. In that case the microphones were recessed behind a Kevlar cloth to suppress interference from boundary layer flow on the tunnel walls.

Despite the fact that closed-test-section wind tunnel showed good aerodynamic performances, drawbacks were seen in the boundary layer interference on signal-to-noise ratio as well as 
the high level of acoustic attenuation and reflection on solid walls. $^{2}$ To either overcome or reduce these disadvantages, efforts should be directed to them, which means at first attempts to control the level of attenuation and reflection on solid walls by avoiding scattering of unwanted sound sources in the closed circuit. Secondly, and more important, is to find a way to improve the signal-to-noise ratio by diminishing the boundary layer effects, mainly over flushed array of microphones. A lot of refurbishing work and technical improvements have been presented on literature in the last decade about these attempts. Authors ${ }^{10}$ applied advanced methods for aeroacoustic imaging associated with designed liners on the walls of the test section with suppression of background noise by $5 \mathrm{~dB}$ at the averaged flow speed. The work of ${ }^{11}$ presented an anechoic system for the closed-test-section which consists of side walls made of stretched, thin-weave cloth. This cloth-window allowed sound to pass through the walls into the anechoic chambers. The work of ${ }^{12}$ depicted the use of phased microphone array for obtaining source maps of a cambered airfoil in a closed-section wind tunnel heavily contaminated with background noise. In their work, a phased microphone array was installed with recessed microphones behind an acousticallytransparent flat Kevlar window.

As seen in the work of, ${ }^{13}$ the concept of hybrid anechoic wind tunnel is becoming effective since it features a test section which is good for aerodynamics while keeping the ability to use it for acoustic measurements. One of the first uses was presented by ${ }^{14}$ and, ${ }^{15}$ which was based on the original idea of ${ }^{16}$ extended the application of tensioned Kevlar cloth to the walls of the wind tunnel transforming it in acoustically transparent while keeping the minimum rigidity necessary for aerodynamics measurements. The work of ${ }^{17}$ discussed the benefits of recessing array microphones in different cavities and with a tensioned screen protection. Another example of aeroacoustic measurements made with microphone arrays behind an acoustically transparent Kevlar window for a propeller can be found in. ${ }^{18}$

One intermediate step into this approach of converting an originally aerodynamic wind tunnel in a hybrid concept is presented in this work. The LAE-1 wind tunnel of the Aerodynamics Laboratory from Aeronautical Engineering Department of EESC-USP (São Paulo University), is used for both aerodynamic and aeroacoustic testing as part of the major program between Brazilian Aircraft Industry (EMBRAER) on aeroacoustics, called Silent Aircraft. To perform such tests, in 2008, an upgrade was carried out to decrease background noise and the implementation of a microphone array as is described in $^{19}$ and. ${ }^{20}$ When developed noise reduction technologies were applied to the models, their noise spectra were very close to the wind tunnel background noise showing a poor noise ratio between the model's signal to background. Thus, to improve the capacity of aeroacoustic testing, a set of tests were carried out with single microphones placed at different locations inside the WT circuit as well as through beamforming phasedarray measurements to characterize the background noise at the test-section and others wind tunnel locations for different flow speeds. Once identified, the main noise sources, some improvements (acoustic treatment) were applied inside the sec-

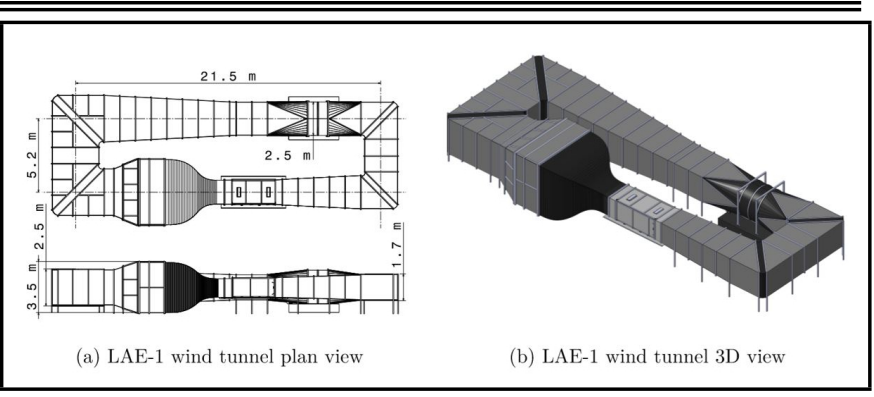

Figure 1. LAE-1 wind tunnel overview.

tions to help reducing the background noise levels and to make it available to perform aeroacoustic measurements with reliability and capacity for dealing with different problems. Also, a simple concept of an acoustically transparent beamforming antenna was investigated using a recessed microphone covered with a Kevlar-cloth as well as acoustic foam.

The work is structured as follows: Sec. 2 provides an overview for the test-facility. The methodology for acoustic measurements with single and multiple microphones is presented in Sec. 3. An analysis of the effect of recessing a microphone behind a Kevlar-cloth and acoustic foam is given on Sec. 4. Section 5 is devoted to present the modifications included in the wind tunnel to help decreasing the background noise levels. Section 6 provides the results and discussions. Finally, Sec. 7 gathers the most important conclusions.

\section{WIND TUNNEL FACILITY — OVERVIEW}

The LAE-1 wind tunnel, located at the Laboratory of Aerodynamics (LAE) of São Carlos School of Engineering, University of São Paulo (EESC-USP), was used for the tests. It is a closed-circuit wind tunnel of $1.3 \mathrm{~m} \times 1.67 \mathrm{~m} \times 3 \mathrm{~m}$ (height, width, and length) working section, respectively. It has an 8-blade fan driven by a $110 \mathrm{HP}$ electrical motor, with seven straighteners located downstream the fan and two $54 \%$ porosity screens located before the contraction cone for turbulence reduction. ${ }^{21}$ Such conditions allow the wind tunnel to achieve velocities of up to $45 \mathrm{~m} / \mathrm{s}$ with a $0.21 \%$ turbulence level at the working section. Figure 1 shows its top and isometric views.

Initially, the wind tunnel was designed for aerodynamic tests, however, it was adapted for aeroacoustic measurements by means of two acoustic treatments applied on the walls and fan. The first modifications consisted in the application of melamine foam on walls as marked with red color in Fig. 2, which promoted a $1.5 \%$ velocity reduction at $31 \mathrm{~m} / \mathrm{s}$ as illustrated in the work of. ${ }^{19}$ The second acoustic treatment was the insertion of a baffle (element in blue in Fig. 2) in the small connector downstream the test-section. One last modification was performed by adding a polyurethane foam in regions where the gap between the fan blade and the wall was longer than $3 \mathrm{~mm}$, according to. ${ }^{20}$ Figure 3 shows the region of larger gap with and without the trip treatment.

\section{METHODOLOGY FOR WT NOISE SOURCE IDENTIFICATION}

The noise source identification in the LAE-1 wind tunnel was carried out by using two distinct approaches which are 


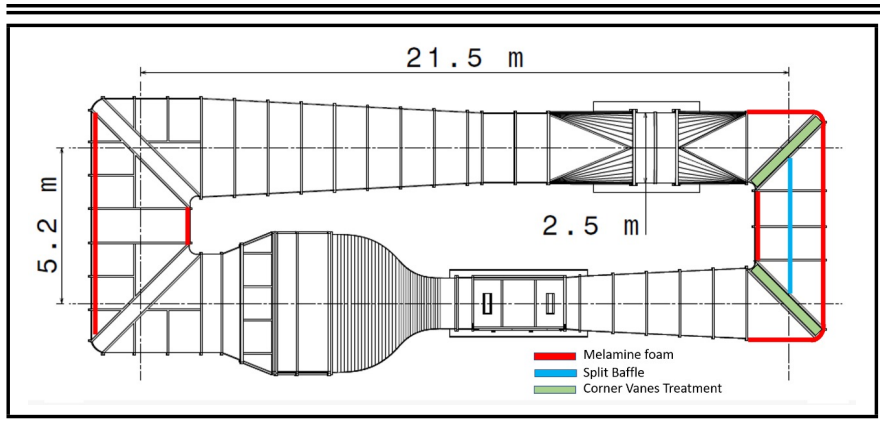

Figure 2. Acoustic treatment along the circuits of LAE-1 Wind Tunnel.

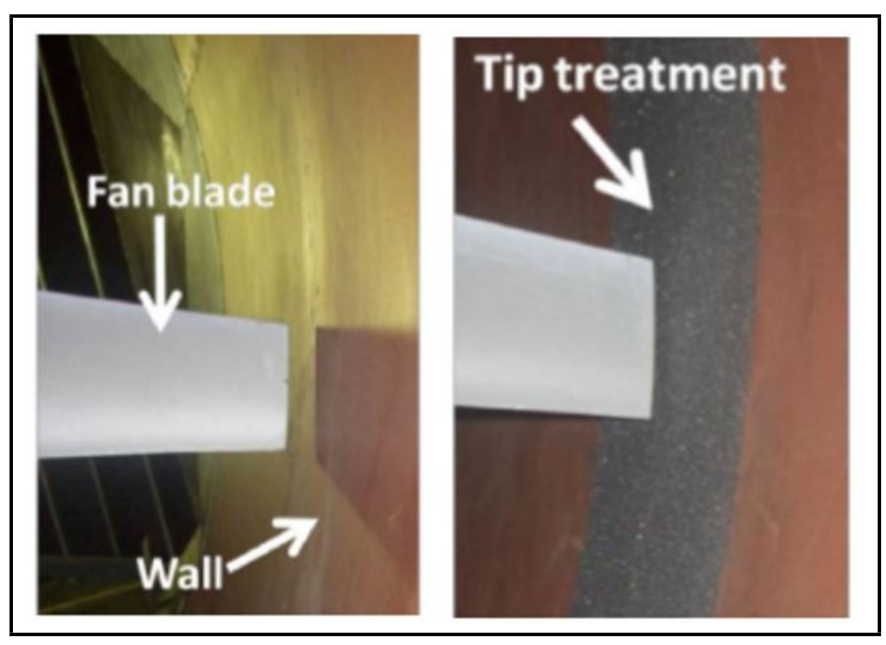

Figure 3. Modifications applied to the drive-system - blade tip treatment. After. ${ }^{19}$

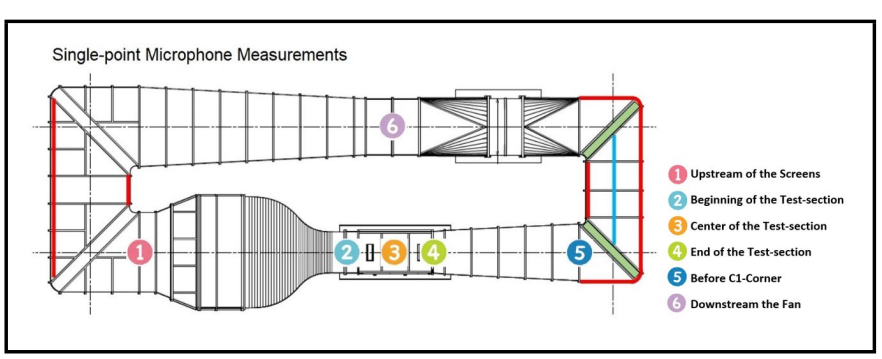

Figure 4. Single microphone positioning at different WT locations.

described in the following sub-sections:

\subsection{Single Microphone Measurements}

Single-point background noise measurements were carried out by using a microphone G.R.A.S. 46BD installed in a stand (mounting) at different WT locations as well as in the middle of the test-section as illustrated by Fig. 4. Acquisition was performed through a PXI system ${ }^{\circledR}$, composed by four NI PXIe4496 boards with a capacity to hold simultaneously 64 analog inputs with 24 bits' resolution and maximum of $204.8 \mathrm{kHz}$ sample rate. This approach was very important to identify and locate the main potential noise sources coming from different locations inside the WT at different flow speeds, respectively of $[9.8 \mathrm{~m} / \mathrm{s}, 15.3 \mathrm{~m} / \mathrm{s}, 20.9 \mathrm{~m} / \mathrm{s}, 26.7 \mathrm{~m} / \mathrm{s}, 35.2 \mathrm{~m} / \mathrm{s}, 40.9 \mathrm{~m} / \mathrm{s}$ and $46.4 \mathrm{~m} / \mathrm{s}$ ].

At first, two different stands (mountings) were tested to verify the one with minimum interference in the microphone measurements. The two tested mountings are presented in Fig. 5

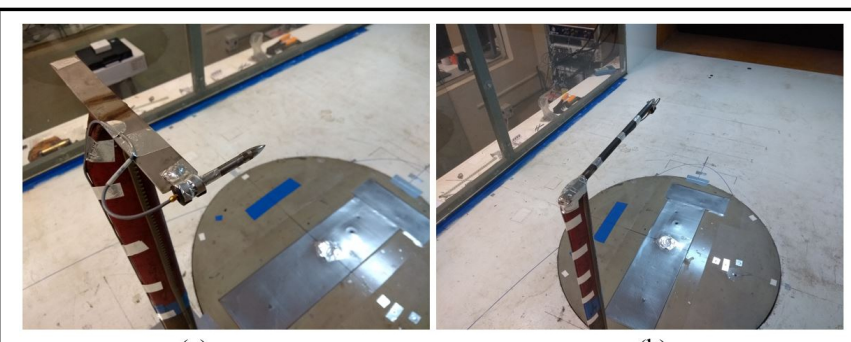

(a)

(b)

Figure 5. Two microphone's stand tested. (a) with flat plate; (b) with advanced probe.

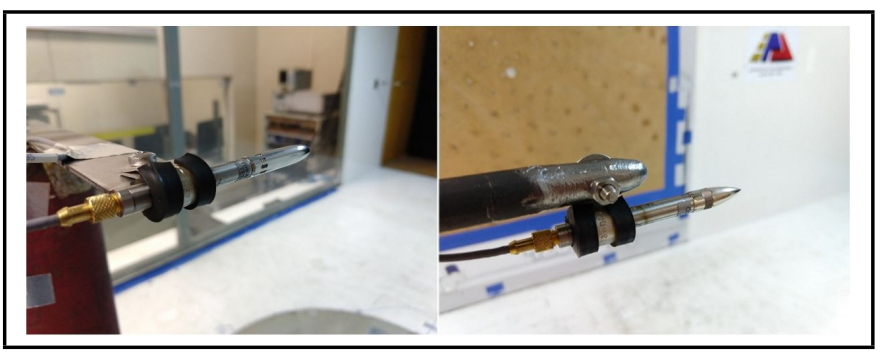

Figure 6. Two different nose cones tested with microphone G.R.A.S.46BD $1 / 4$.

and Fig. 7 and are made by steel with an advanced rod to hold the microphone ahead of it.

As mentioned, a G.R.A.S. 46BD $1 / 4$ inch microphone with a flat response up to $70 \mathrm{kHz}$ was used to assess the background noise. Due to high total pressure fluctuations inside the flow, the microphone diaphragm was covered by a so-called "nose cone". Two different nose cones were used, one from G.R.A.S. and other from B\&K acoustic instruments - Fig. 6 .

It is known that nose cones could affect the measurement itself due to its forebody. ${ }^{22}$ The forebody protects the fragile microphone diaphragm and reduce flow-induced noise while the response becomes virtually omnidirectional at frequencies below $5 \mathrm{kHz}$.

To accomplish the background noise measurements with flow, the microphone with the B\&K nose cone was mounted at three positions within the test-section, upstream of the turning vanes (downstream of test-section), downstream of the fan and upstream of the screens, as illustrated by Fig. 4 and Fig. 7, which illustrates some pictures of the single microphone mounted at different locations along the wind tunnel circuit.

\subsection{Phased-Array Microphone Measurements}

Phased-array microphone measurements were carried out with a 61-microphone antenna flush-mounted on the tunnel side wall (sideline location). All microphones were of type G.R.A.S. 46BD cartridges, combining a pressure transducer (40BD) and a pre-amplifier (26CB). The instrumentation was designed for a flat response from $7 \mathrm{~Hz}$ to $40 \mathrm{kHz}$ ( $1 \mathrm{~dB}$ loss) or from $4 \mathrm{~Hz}$ to $70 \mathrm{kHz}$ (2 $\mathrm{dB}$ loss). The microphone array was designed with a modified spiral geometry ${ }^{23}$ to allow measurements at a large frequency band. The 61 microphones were positioned in a $0.8 \mathrm{~m} \times 0.8 \mathrm{~m}$ wall as seen in Fig. 8. Acquisition was also performed through the PXI system ${ }^{\circledR}$ as already commented. 


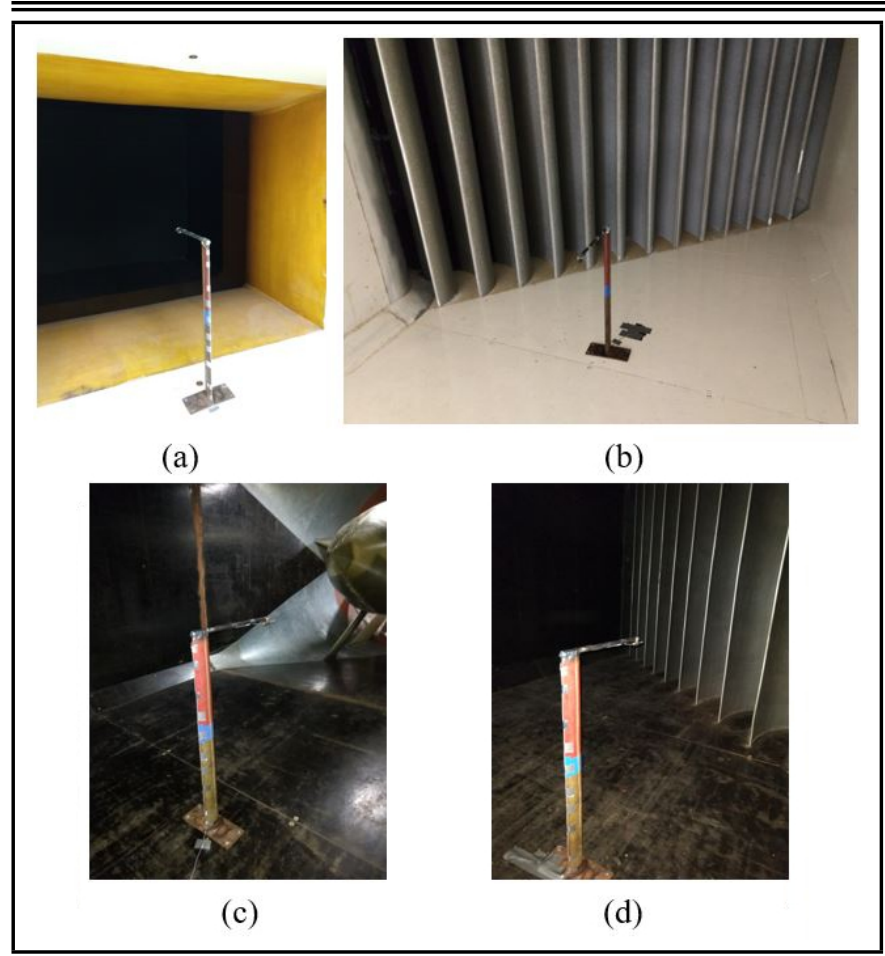

Figure 7. Single microphone measurements at different WT locations: (a) Beginning of test-section; (b) Downstream the test-section; (c) After the drivesystem; (d) Upstream the screens.

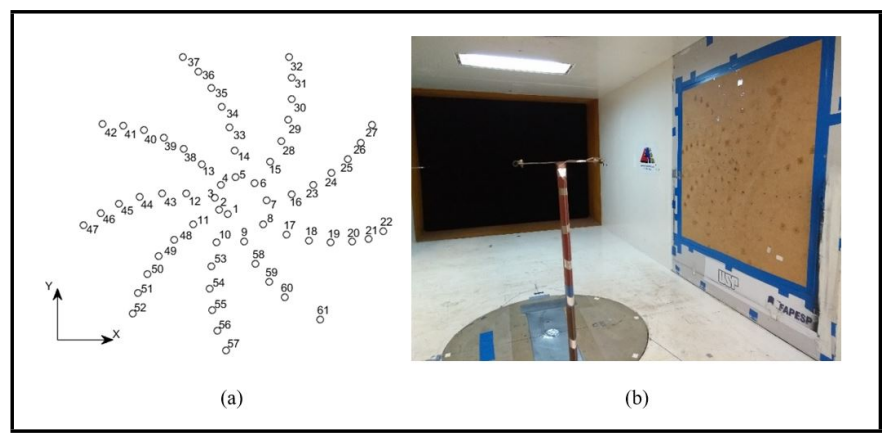

Figure 8. (a) Description of microphones-array; (b) LAE-1 phased-array antenna.

\section{METHODOLOGY FOR TESTING AN ACOUSTICALLY TRANSPARENT WALL}

Based on the data of Jaeger et al. ${ }^{16}$ it was identified potential for improvement in reducing flow-induced noise of wallmounted microphones using a stretched Kevlar over microphones recessed behind the flow surface. Based on the theoretical estimation, Eq. (1) given by: ${ }^{16}$

$$
20 \log 10\left(\Delta p_{B L}^{\prime}\right)=-4.3 \frac{4 \pi f y}{U_{c}}
$$

where $\Delta p_{B L}^{\prime}$ was the boundary layer pressure disturbance, $f$ was the frequency, $U_{c}$ was the flow velocity and y was the depth. The signal decayed faster with frequency as microphones were separated by boundary layer, i.e., they were recessed inside the cavity. As an example: To $f=3400 \mathrm{~Hz}$, $y=12.7 \mathrm{~mm}$ and $U_{c}=33 \mathrm{~m} / \mathrm{s}$ the decay would be $-70 \mathrm{~dB}$. For additional details the reader should verify. ${ }^{16}$

Based on the idea of recessed array mounting, it was decided to carry out a simple test with a single G.R.A.S. 46BD

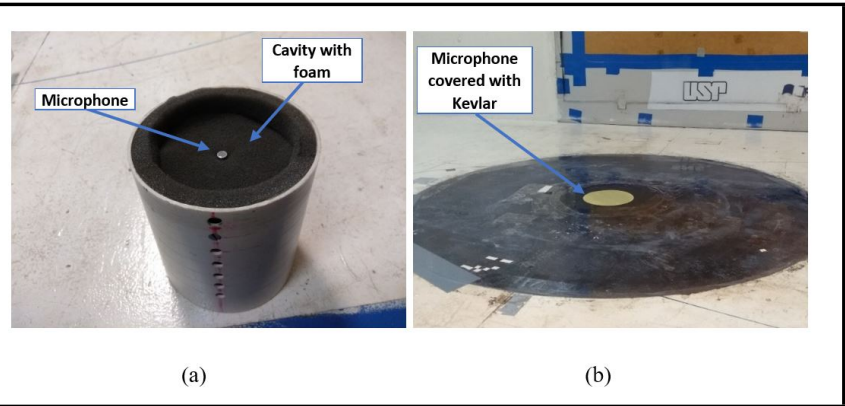

Figure 9. (a) Cylindrical cavity for simulating microphone recessing and (b) recessed microphone mouting in the WT.

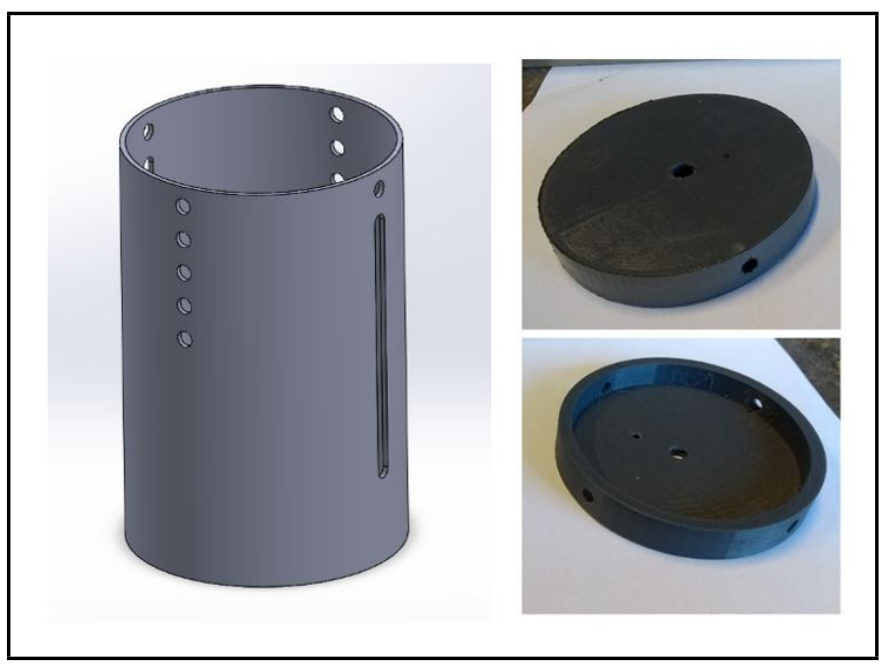

Figure 10. Cylindrical mounting with pre-defined position for microphone and cavity support.

$1 / 4$ inch microphone inside a cylindrical cavity. The idea was to test a Kevlar cloth and melamine foam coverage inside the cavity. Flush-mounted configuration was also tested. Figure 9 illustrates the cylindrical cavity and the recessed microphone assembled in the test-section of LAE-1 wind tunnel.

As observed in Fig. 9, a cylindrical body made by PVC has been manufactured to include a single microphone for performing the tests. The body had holes and sliders to adjust the cavity at different heights. Two different microphone supports were built to verify the effect of foam wall-covering inside the cylindrical cavity, as illustrated on Fig. 10.

The tests were performed with different microphone installations either according to the recession inside the cavity or the covering with Kevlar cloth / melamine foam. The test-section was empty with the microphone array located at the side wall and the single microphone mounting in the ground placed at the center table. The inverter frequency for the drive-fan was set from $20 \mathrm{~Hz}(\sim 10 \mathrm{~m} / \mathrm{s})$ up to $35 \mathrm{~Hz}(\sim 35 \mathrm{~m} / \mathrm{s})$. The following tests were carried out according to configurations (A) up to $(\mathrm{G})$ :
(A) Microphone wall-flushed (no cavity)
(B) Microphone recessed $(12.7 \mathrm{~mm})+$ Kevlar
(C) Microphone recessed (12.7 mm) + Kevlar + Foam
(D) Microphone recessed (12.7 mm) + Kevlar + Foam + Cap
(E) Microphone recessed (25.4 mm) + Kevlar + Foam + Cap 
(F) Microphone wall-flushed + Cap

(G) Microphone recessed (12.7 mm) - wall-flushed (no Kevlar on top)

The results will be presented based on microphone spectra for each configuration. The comparative analysis was performed for those situations were gain in terms of noise reduction was achieved. The test conditions were kept during the whole test campaign - wind speed / Mach number and temperature (less than $2^{\circ} \mathrm{C}$ of variation) providing a total of 28 runs.

\section{WIND TUNNEL BACKGROUND NOISE IMPROVEMENTS}

Noise treatments for the LAE-1 wind tunnel were studied and investigated from literature following ideas of incorporating sound absorbing material or any other technical concept to reduce the noise levels inside the test-section, especially at moderate frequencies ( $1000 \mathrm{~Hz}$ up to $4000 \mathrm{~Hz}$ ). Some of these ideas are summarized in sequence:

1. Recession of the microphones based on the data of: ${ }^{16}$ it was identified potential for improvement in reducing flow-induced noise of wall-mounted microphones using a stretched Kevlar over microphones recessed behind the flow surface - Fig. 9;

2. Another possible configuration is a combination of foam material (to treat the higher frequency range) and membrane or compound panel absorbers (to treat the lower frequency range). This combination is already implemented on LAE-1 between the corners $\mathrm{C} 1$ and $\mathrm{C} 2$, Fig. 11, however, it is possible to enhance it as described in the work of. $^{24}$

3. A more robust and high-impact modification would be the use of micro perforated panel absorber in the circuitleg close to $\mathrm{C} 1$ and $\mathrm{C} 2$. Micro perforated panel absorbers are tuned for absorbing acoustic energy within small $(<1 \mathrm{~mm})$ holes or slits as illustrated below. Micro perforated absorbers operate basically like Helmholtz resonators. A more detailed study is required to design the micro perforated panel to LAE-1 wind tunnel. From theoretical standpoint it is quite feasible and efficient in terms of noise reduction since the panel is geometrically set by the noise-frequency content.

All the possibilities above described could work to improve the noise levels in LAE-1, however, due to the timing as well as the need of a solution of low impact and low cost, only the recession of microphones and inclusion of sound absorbing material was evaluated at the time. The proposed modifications are described in the sequence:

\subsection{Corner-Vanes and Sidewall Lining}

Figure 12 illustrates in the LAE-1 circuit the regions where the modifications for sidewall-lining were applied. As seen, the splitter-plate was already incorporated in the circuit. This

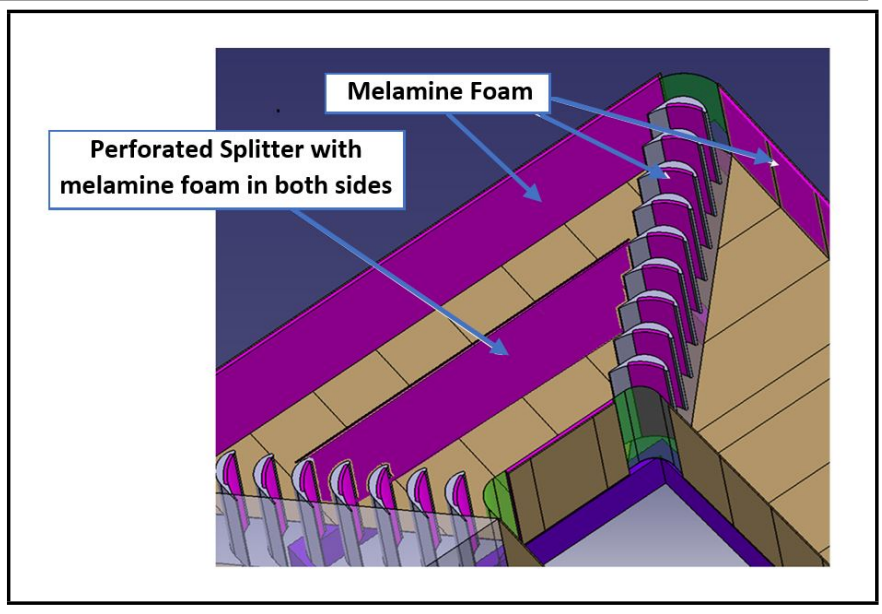

Figure 11. Description of treatment in the C1-C2 connection in LAE-1.

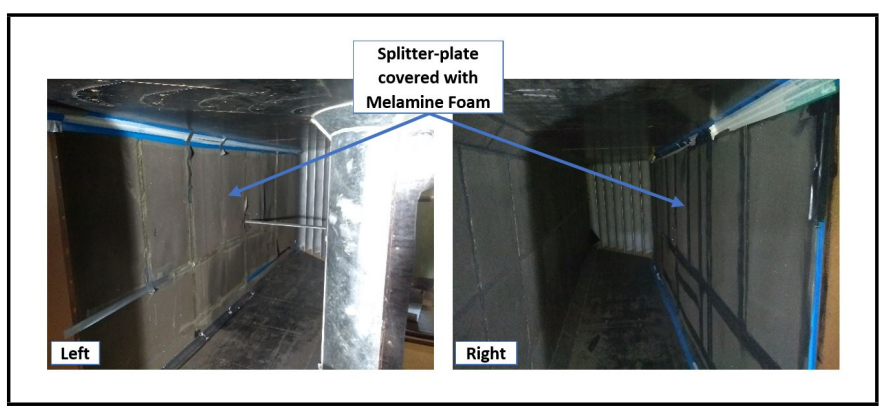

Figure 12. Regions where acoustic modifications were applied in LAE-1 WT.

splitter-plate already has melamine foam, according to the work of Santana et al., ${ }^{19}$ however, it was necessary to review the installation and correct the panels as well as to improve the quality of the foam in some places. It is important to say that the sidewall lining had the same material as seen in the splitter-plate.

However, the major modification was applied to the redesign of the corner-vanes ( $\mathrm{C} 1$ and $\mathrm{C} 2)$, where the airfoil profile, which is based on the work of Collar, ${ }^{25}$ was changed to incorporate a $20 \mathrm{~mm}$ melamine foam in the pressure side. Figure 13 illustrates the modification in the corner-vane profile, showing the recession region where the melamine foam was applied.

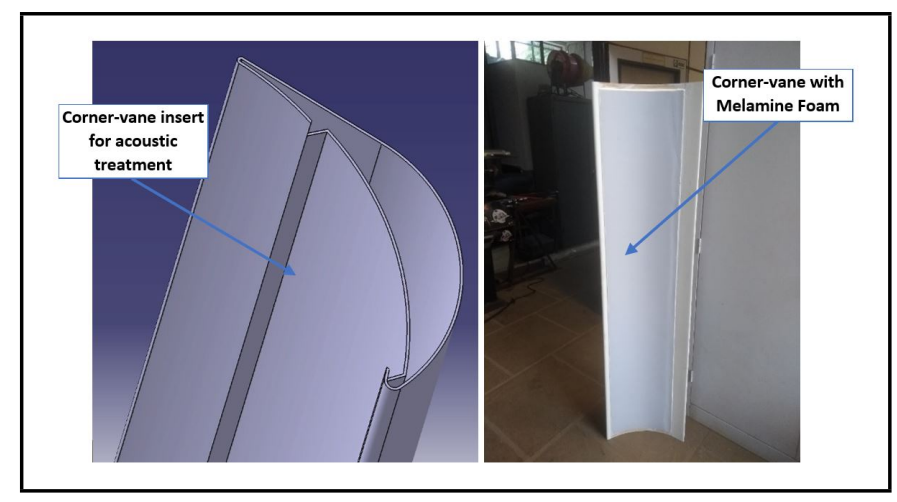

Figure 13. Modification in the profile of the $\mathrm{C} 1$ and $\mathrm{C} 2$ corner-vanes to receive the melamine foam. 


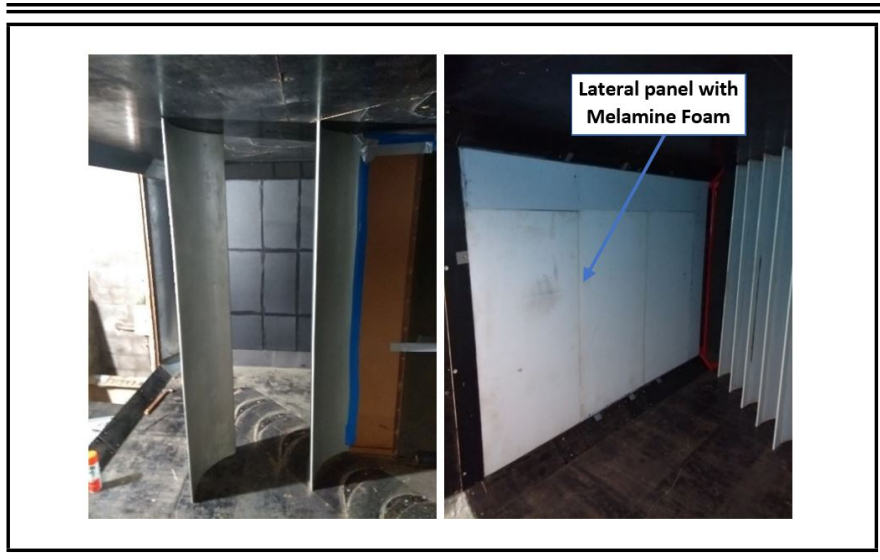

Figure 14. Side wall upgrade by applying the melamine foam (white panel).

\subsection{Sidewall Lining (Upstream Fan-Drive System)}

The absorbing material (melamine foam) was used to cover the lateral walls upstream the fan-drive system, including both round-corners in the first and second elbows in the smallconnector WT circuit. At the time the micro perforated panel was not used to cover the absorbing material, but it is understood that this would help to absorb acoustic energy while protecting the melamine foam against deterioration. Both lateral walls were recessed to incorporate a $50 \mathrm{~mm}$ panel of melamine foam. Figure 14 illustrates the upgrade in the sidewall region, by applying the melamine foam. As could be seen, the 13 corner-vanes were replaced at C2 corner and the lateral panel upstream the fan-drive system was installed covering approximately $1.48 \times 2.07$ square meters of acoustically treated area.

After this work, the WT was ready to be used again for the test-campaign of this research. It was expected that these modifications put together could bring some improvements to the noise levels in the test-section.

\section{RESULTS}

\subsection{Single Microphone Data}

Before showing the results for the different locations of the microphone within the wind tunnel circuit, the impact of using different nose cones is provided for a wind speed of $35 \mathrm{~m} / \mathrm{s}$ with the microphone stand placed in the middle of the testsection. Figure 15 shows the spectra comparison for both measurements with the B\&K and G.R.A.S. type nose cones.

According to, ${ }^{22}$ the nose cone could induce noise at higher frequencies mainly due to the shear layer developing at the forebody and cavity tones in the element-sensor. After measurements and data reduction, it was possible to identify that the nose cone started to affect the background noise measurements at St $\sim 0.7$ (close to $5 \mathrm{kHz}$, as expected). What was surprising, was the effect of the design of the forebody in the measurements. As seen in Fig. 15, with the use of B\&K nose cone, the results were much better when compared to G.R.A.S. configuration. For the B\&K nose cone the hump in curve started in $11 \mathrm{kHz}$. Based on the results, the final background noise assessment was carried out with the use of $\mathrm{B} \& \mathrm{~K}$ nose cones.

Figure 16 presents the background noise measurements for the G.R.A.S. 46BD $1 / 4$ inch mounted with the advanced probe

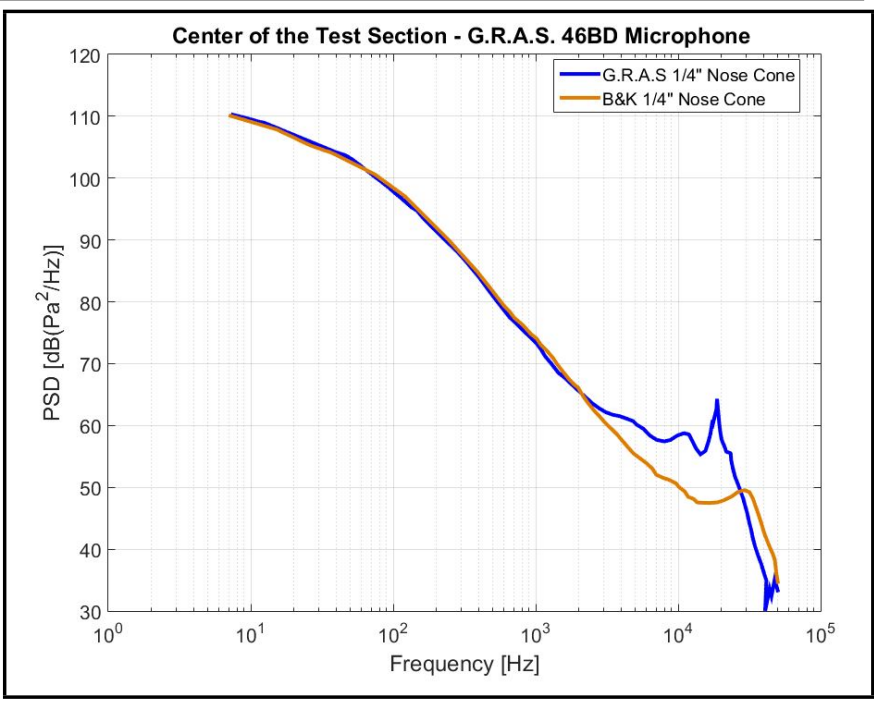

Figure 15. Nose cone influence in the background noise measurements at LAE-1.

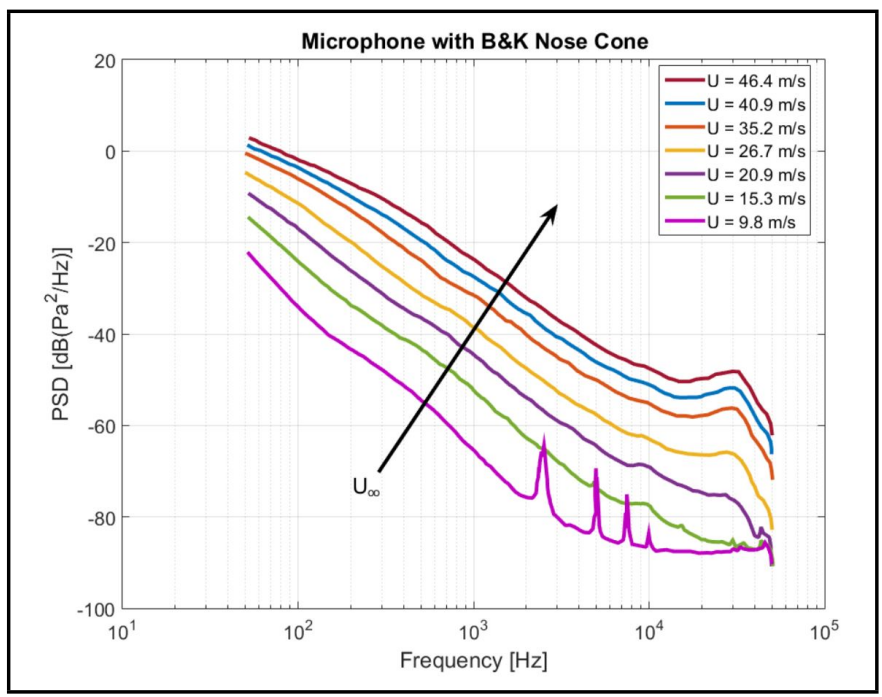

Figure 16. microphone.

for different wind speeds at the test-section. The results in Fig. 16 were consistent for wind speeds above $9.8 \mathrm{~m} / \mathrm{s}$. Specifically at $9.8 \mathrm{~m} / \mathrm{s}$ some peaks were identified in the spectrum which would come either from electrical noise present in the acquisition system or from motor noise or other components in the closed-circuit.

At the end of these measurements, a noise source identification was taken in the test-section by covering any small holes, slits or breaches with silver-tape. Even the aperture between the turning-table and the floor of the wind tunnel was sealed. Additionally, the WT venting-windows were also sealed. Another test was taken for a wind velocity of approximately $35 \mathrm{~m} / \mathrm{s}$ and the final background noise levels were gathered, as presented in Fig. 17. Based on the results in Fig. 17, it is possible to affirm that additional noise is not coming from the test-section. It is interesting to observe that with the ventilation windows closed the noise levels were slightly higher. Sealing the vents was probably causing leaking at different positions along the WT circuit, possibly causing the increased levels. 


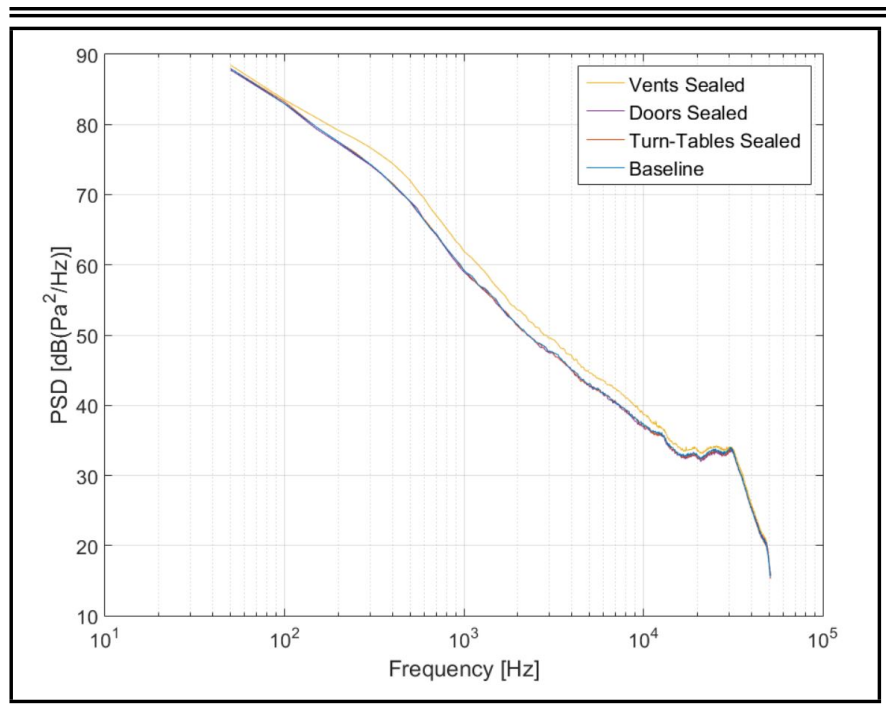

Figure 17. Background noise levels for different sealing at the test-section.

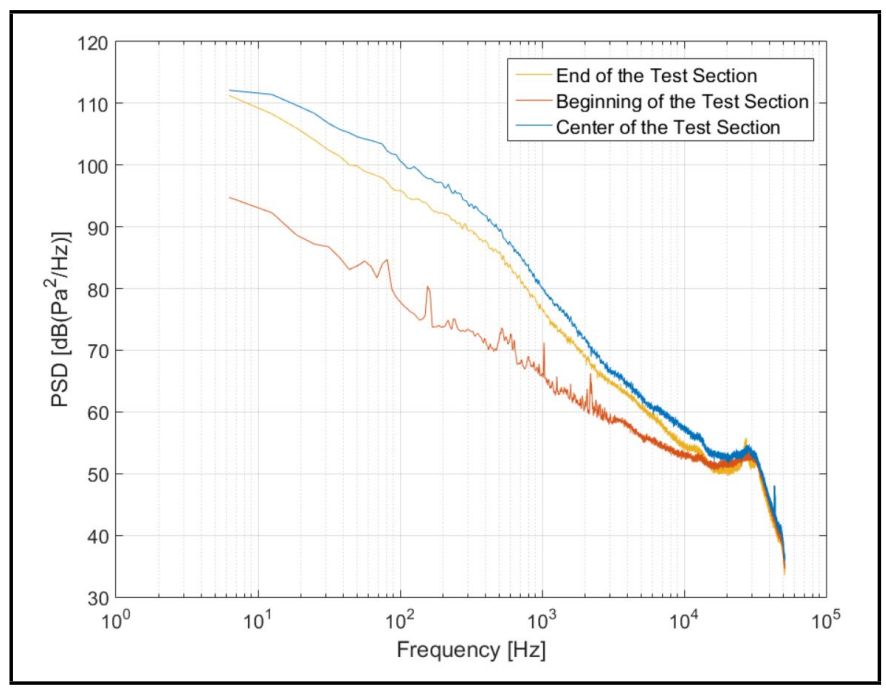

Figure 18. Background noise levels at different locations in the test-section of LAE-1.

To accomplish the background noise measurements with flow, the microphone with the $\mathrm{B} \& \mathrm{~K}$ nose cone was mounted at the six positions within the WT, as previously seen of Fig. 4 . Figure 18 presents the spectra from the three measurements with the microphone placed at the beginning of the test-section, in the middle of it and at the end of the test-section, respectively.

The noise levels at the test-section are mainly due to the noise emitted by the drive-system which propagates towards the back (exit) of the test-section due to the broadband nature. The spectra upstream the test-section has presented lower levels when compared to the other two positions. The increase in the noise levels are due to the boundary layer being developed inside the test-section. It is also possible to identify in the spectra the blade passage frequency (BPF) around $90 \mathrm{~Hz}$ and its multiple tones.

Finally, noise measurements were taken with the microphone at three positions within the WT, upstream of the turning vanes (downstream of test-section), downstream of the fan and upstream of the screens. These data were compared with the spectrum from the microphone placed at the middle of the

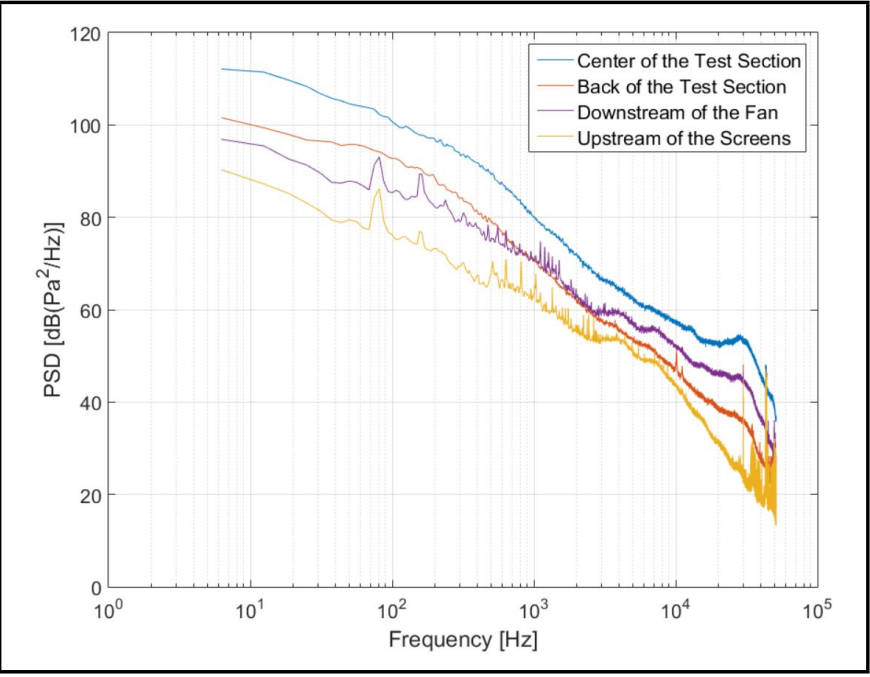

Figure 19. Background noise levels at different locations in the closed-circuit of LAE-1.

test-section as illustrated by Fig. 19.

The noise that is coming from upstream the test-section has lower levels and contain tonal components from fan. It is possible to verify that the noise levels are increased when reaching the test-section and decrease after the test section. Here, it is important to say that, apart from the fan noise, boundary layer noise is another significant source of the background noise at the test section and in this case is increasing the broadband content of the spectra.

\subsection{Phased-Array Microphone Data}

To complement the analysis, the background noise was investigated by assessing its influence on the measurements, regarding spectra and Mach scale factor. ${ }^{26}$ Several measurements were performed for obtaining the background noise in the LAE-1 wind tunnel test-section. Figure 20 shows the wind tunnel sound pressure levels measured for different Mach numbers (usual to low-speed aeronautical configurations). Frequency and Mach scales are represented by Strouhal numbers calculated with the free-stream velocity. The first spectral results in Fig. 20 (a) are showing the background noise against Strouhal number, giving an insight on the frequency scales with velocity. High-frequency peaks are caused by probably caused by the power inverter that rotated the fan of the wind tunnel. No peaks were detected between low to medium frequencies, which provided a broadband noise in all range with higher levels at low and mid frequencies.

Mechanisms of background noise sources were investigated by the Mach scale factor (N). Fig. 20 (b) shows the Mach scale factor as an average of the five velocities used in this test and Fig. 20 (c) displays a comparison between the OASPL obtained for the Mach numbers tested and expected curves. The results are in concordance with those expected between monopole and dipole scale, since most of the background noise sources are of dipole type, e.g., fan noise and boundary layer noise. According to Soderman and Allen ${ }^{22}$ the main sources of wind tunnel background noise are the fan system (variables that contribute to fan noise are hub and tip diameter, rotational speed, number of blades and blade-pitch angle), wall bound- 
ary layer, test-dependent hardware, and microphone self-noise (boundary layer effect over the microphones, screen or cavity perturbations, electronic noise, and free-stream turbulence).

Acoustic data by averaging 61 microphones was also acquired concomitantly with the single microphone measurement in the stand. The comparison between single microphone and averaged acoustic data is presented in Fig. 21.

According to Fig. 21, beamforming seems to be predicting noise levels smaller that the phased-array correlation theory. One of the reasons for that could be associated to possible help from the spatial filtering applied at the BF post-processing. In Fig. 21, the source power integration was performed using the hole test section area, along a plane in the centre of the test section using the hole test section area ( $X=3 \mathrm{~m}, Y=1.2 \mathrm{~m})$. The SPI divides the source strength at each source position by the integration of the beamwidth estimated at the given location over the hole plane. For more details of the procedure, the reader is guided to the work of Sijtsma. ${ }^{27}$ A single microphone with $\mathrm{B} \& \mathrm{~K}$ nose cone measurements presents higher noise levels, especially for frequencies above $5 \mathrm{kHz}$.

\subsection{Recessed Microphone Data}

Spectral analysis was performed to identify the best assembly for the microphone in a further design of a phased-array. As previously depicted, 28 runs were performed with different positioning of a single microphone wall-flushed and inside a cavity covered with Kevlar and/or melamine foam. Figure 22 shows the spectra comparison for all tested configurations $(A-G)$. Three configurations $(A, F$ and $G)$ that were wall-flushed with and without the cavity have shown the higher noise levels as expected, since the microphone is directly subjected to the WT boundary layer formed in the floor of the test-section. Keeping the cap over the microphone membrane has also shown some impact on the very high frequency range as illustrated by Configuration $(\mathrm{F})$ while recessing the microphone in a wall-flushed configuration $(\mathrm{G})$ has shown impact on the very low frequency range. Obviously, those configurations are not candidates for an assembly in a phased-array configuration and they have been tested only as a parameter to confirm the expected acoustic response of this experiment.

As we recess the microphone and add the Kevlar or melamine cloth, as seen in configurations (B) to (E), a big decrement in the noise leves is seen in the curves in accordance with the original tests performed by Jaeger et al. ${ }^{16}$ For those configurations it appears that the flow-induced noise due to direct exposition of the microphone membrane has been reduced dramatically with the best configurations being the (C) and (D), respectively.

Based on the results presented in Fig. 22, the following discussion and observations were registered at the time:

Early studies have shown that if the actual background noise could be reduced, less data and fewer time averages are required to resolve potential sources. Previous studies suggested that the ideal array surface treatment requires a thin, light, porous surface with low acoustic impedance that is also strong enough to act as an aerodynamic surface to separate unsteady flow from the bare microphone diaphragms. Comparisons with

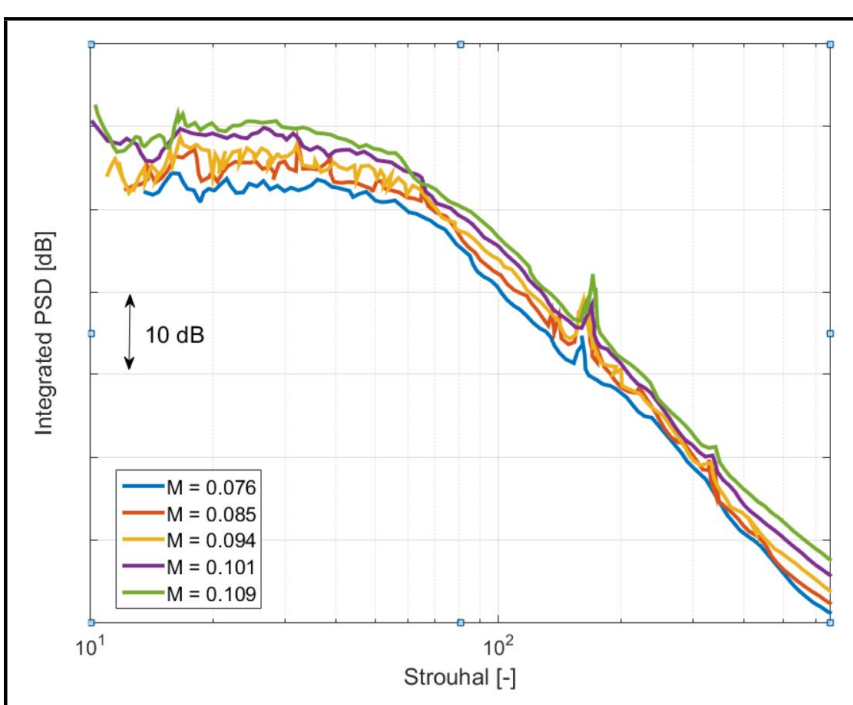

(a) Background noise vs Strouhal.

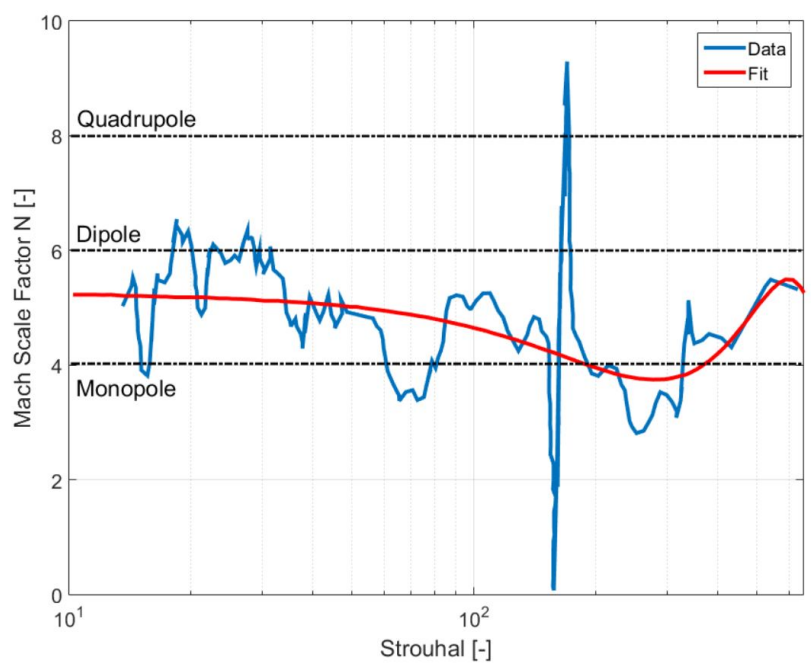

(b) Mach Scale Factor

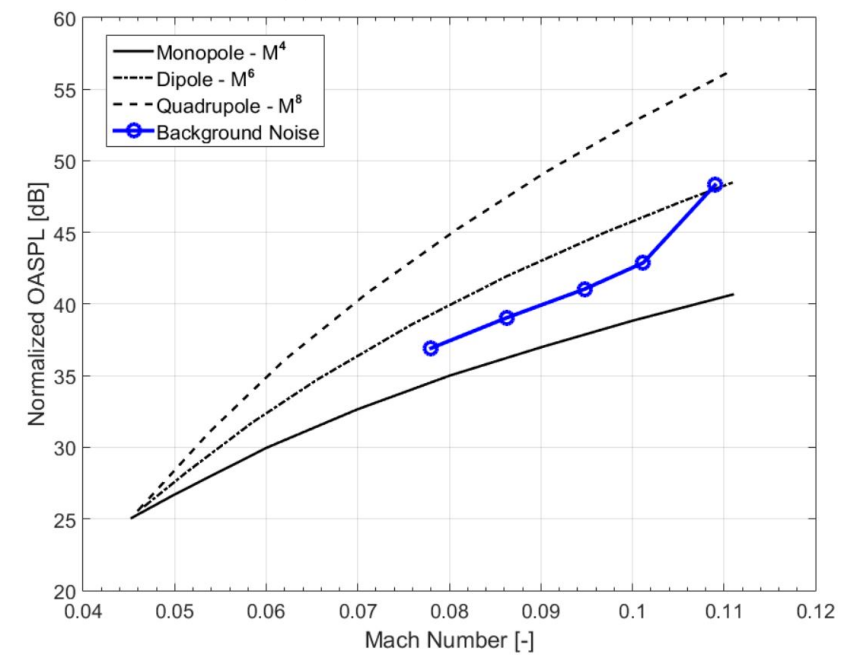

(c) OASPL (Filtered Overall Sound Pressure Level)

Figure 20. 61-microphone array measurement of the background noise levels from LAE-1. 


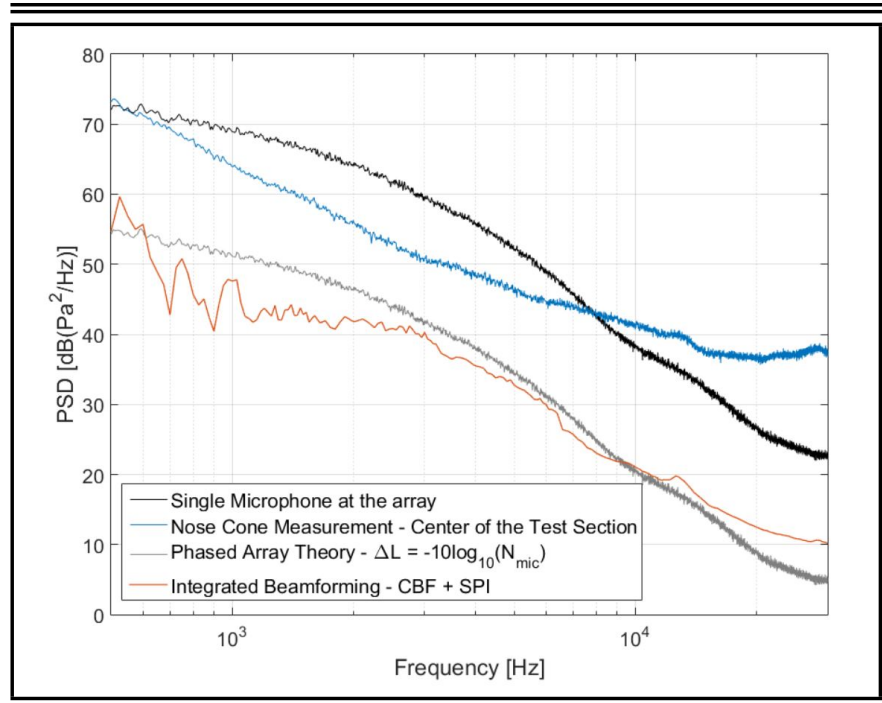

Figure 21. Background noise levels from single microphone versus averaged acoustic data at the test-section.

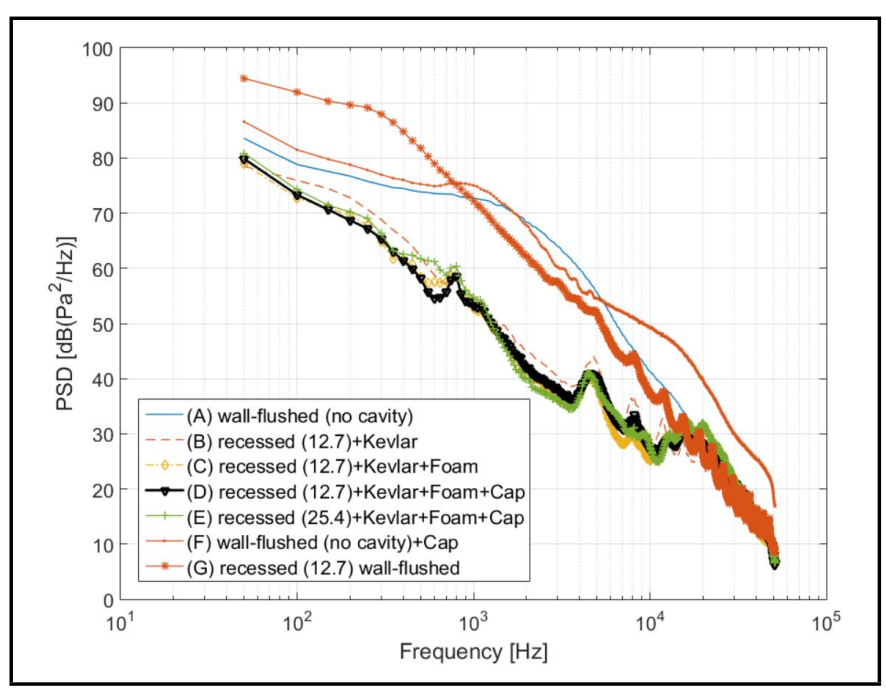

Figure 22. Comparison of background noise measurement with single microphone mounted in different configurations $(\mathrm{A}-\mathrm{G})$ at Mach number 0.1

a flush-mounted and a recessed single microphone inside a cylindrical cavity has shown noise reduction for $300 \mathrm{~Hz}$ up to $10 \mathrm{kHz}$. The inclusion of melamine foam inside the microphone cavity added extra-noise reduction at the same frequency range. Tonal noise component was identified in the spectra from configurations with the presence of Kevlar. However, this tonal noise component is still below the noise measured with flush microphones. The tonal noise component is probably associated with flow permeating the flow cavity where the microphone is placed, since there is a gap between the Kevlar protection and the microphone insert. The insertion of the microphone's cap is negative since high frequency content in the spectra increased, probably due to flow-cap interaction. Deeper recession did not show additional noise reduction when compared to $12.7 \mathrm{~mm}$ depth. Drawbacks were identified related to the choice of the Kevlar cloth and how to promote the tension needed to stretch the thin Kevlar weave. The results confirmed that acoustic attenuation was up to $20 \mathrm{kHz}$.

Careful reduction of flow-induced background noise can greatly increase the utility of microphone arrays for evaluating

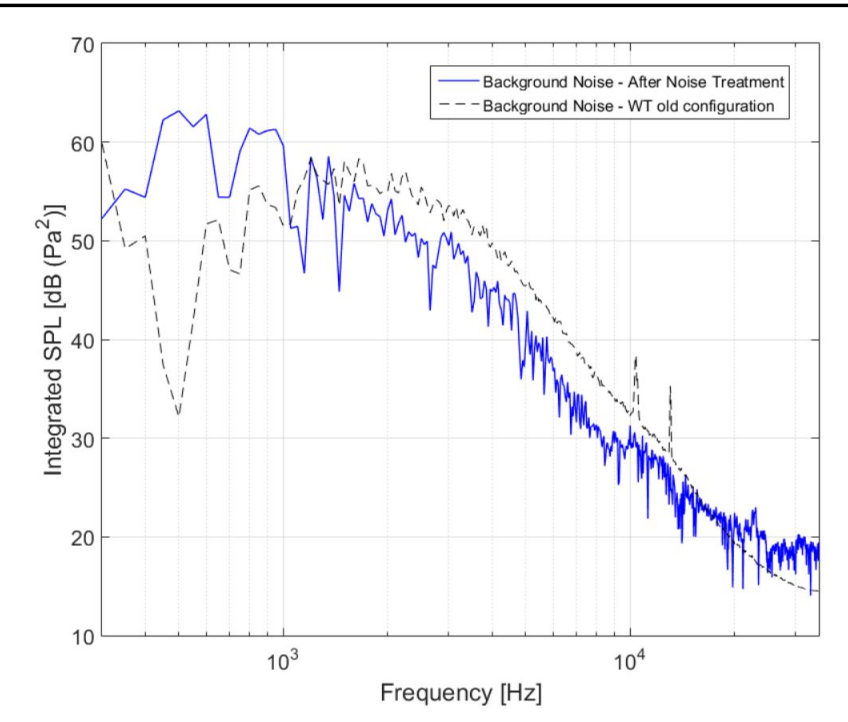

Figure 23. Comparison of background noise measurement before and after all acoustic modifications in LAE- $1 \mathrm{WT}-35 \mathrm{~m} / \mathrm{s}$.

sources in closed wind tunnels. Compared to flush-mounted microphones, the reduction of background noise at frequencies below $3500 \mathrm{~Hz}$ is substantiable and serves to improve the dynamic range of the phased microphone array. It has been identified that tonal noise component may jeopardize the noise reduction (gain) for frequencies above $20 \mathrm{kHz}$, probably as a result of flow interaction with the Kevlar cloth surface.

\subsection{After Noise Treatment In LAE-1 WT}

All the LAE-1 recent acoustic modifications were carried out based on previous studies and tests to minimize the impact of a huge remodeling of the wind tunnel which will bring cost and time to the laboratory. By following some simple steps, it was possible to identify the main noise sources inside the WT circuit and some ideas of minimizing them were implemented, as previously discussed in Section 5. The actual configuration of the LAE-1 WT is depicted in Fig. 4 illustrating the areas where acoustic treatment were incorporated in the sidewalls and splitter-plate, as well as in the pressure side of both sets of corner-vanes in corners $\mathrm{C} 1$ and $\mathrm{C} 2$ (downstream of the testsection). With all these modifications in place, it is possible to re-evaluate the noise levels inside the test-section by means of the phased-array microphone antenna, performing the test at $35 \mathrm{~m} / \mathrm{s}$ with empty test-section - Fig. 23.

As can be seen from Fig. 23, the noise levels decrease close to $5 \mathrm{~dB}$ for a frequency range from $2 \mathrm{kHz}$ up to $10 \mathrm{kHz}$, which is relevant for doing a lot of research in the aeronautical field. However, there are still some issues with the low and high frequency part of the spectrum (below $1000 \mathrm{~Hz}$ and above $10 \mathrm{kHz}$, respectively). It is believed that the next step will improve this drawback, which is the implementation of an acoustically transparent phased-array of microphones. As presented, one of the possible configuration is the antenna with recessed microphones $(12.7 \mathrm{~mm})$ behind a strechted Kevlar-cloth. Another possible approach is to use of a cylinder or airfoil as benchmark data for verification purposes to evaluate the signal-tonoise ratio good enough to guarantee a proper aeroacoustic tests. 


\section{CONCLUSIONS}

A process of improving a low-speed wind tunnel is presented including acoustic treatment at different sidewalls in the small and big connectors, splitter-plate, corner-vanes as well as in the fan blade gap to achieve a lower background noise. To achieve such a goal, single and multiple microphones measurements are carried out inside different locations in the WT circuit for locating the main noise sources. Sound spectra are analyzed and demonstrate that most of the noise present in the test-section was coming from the fan-drive system, by means of the small connector and passing through both sets of cornervanes, and the test-section boundary layer. Based on the data, feasible and low-cost alternatives are implemented for helping the reduction of the background noise such as new acoustically treated corner-vanes and sidewall lining located upstream the drive system. The latest measures of background noise show a reduction of $5 \mathrm{~dB}$ for a frequency range from $2 \mathrm{kHz}$ up to $10 \mathrm{kHz}$ when compared to the old configuration. However, there are still some issues with the low and high frequency part of the spectrum (below $1000 \mathrm{~Hz}$ and above $10 \mathrm{kHz}$, respectively). It was also possible to verify that background noise levels were competitive at low $(<1 \mathrm{kHz})$ and high $(>10 \mathrm{kHz})$ frequencies probably due to the flow scrubbing in over the foam panels.

The idea of including an acoustically transparent sidewall for the test-section is also evaluated through a complementary experiment with a single microphone which was mounted in a flush and recessed configurations. The advent of covering the microphone's cavity by using Kevlar or foam is explored. Different combinations of using Kevlar, foam, microphone cap are tested with and without cavity and taking two different depths $(12.7 \mathrm{~mm}$ and $25.7 \mathrm{~mm})$. The results are very useful and aligned with other literature data, showing a large decrement in the noise levels when recessing the microphone behind a Kevlar cloth over a cavity with $12.7 \mathrm{~mm}$ depth. It is important to say that the approach does not reduce the noise per see but allow for better acoustic imaging. Based on previous data in the literature and on our own experiments, it is possible to propose a new arrangement for the phased-array microphone antenna to be implemented in the future at LAE- 1 wind tunnel.

Measurements of background noise before and after improvements confirm the capacity of performing aeroacoustic tests in the aeronautical field since there was a reduction in the noise levels in the test-section. This reduction in the noise levels would improve the signal-to-noise ratio of a model within a broad range of frequencies which makes the use of the LAE-1 wind tunnel more realible. Future work will consist of testing benchmark models such as either cylinders or airfoils to promote comparison against other WT facilities. A major impact change would be the implementation of a new antenna design behind an acoustically transparent sidewall covered with Kevlar, as well as improvements in the fan-drive system.

\section{ACKNOWLEDGEMENTS}

This first author would like to thank the LAE (Laboratory of Aerodynamics) at São Carlos School of Engineering for re- ceiving him as a visiting professor during the time of this research. Also, the authors thank the Boeing BR\&TB for the funding of this research.

\section{REFERENCES}

1 Gomes, J. Pereira; Bergmann, A.; Holthusen, H. Aeroacoustic wind tunnel design, CEAS Aeronautical Journal, 10(1), 231-249, (2019).

${ }^{2}$ Lv, Jinlei et al. Study on Acoustically Transparent Test Section of Aeroacoustic Wind Tunnel, Journal of Applied Mathematics and Physics, 6(1), 1-10, (2018).

3 Pascioni, K., Reger, R., Edstrand A., Cattafesta L., Characterization of an aaeroacoustic wind tunnel facility, INTERNOISE and NOISE-CON Congress and Conference Proceedings, 249(3), Institute of Noise Control Engineering, (2014).

4 Remillieux, M., Crede E., Camargo H., Burdisso R. A., Devenport W., Rasnick M., Van Seeters P., Chou A., Calibration and demonstration of the new Virginia Tech anechoic wind tunnel, 14th AIAA/CEAS Aeroacoustics Conference (29th AIAA Aeroacoustics Conference), (2008). https://dx.doi.org/10.2514/6.2008-2911

5 Merino-Martínez, R., Rubio-Carpio A., Lima Pereira L. T., van Herk S., Avallone F., Ragni D., Kotsonis M., Aeroacoustic design and characterization of the 3D-printed, open-jet, anechoic wind tunnel of Delft University of Technology, Applied Acoustics, 170, 107504, (2020). https://dx.doi.org/10.1016/j.apacoust.2020.107504

6 Merino-Martínez, R., Sijtsma, P., Snellen, M., Ahlefeldt, T., Antoni, J., Bahr, C. J., Blacodon, D., Ernst, D., Finez, A., Funke, S., Geyer, T. F., Haxter, S., Herold, G., Huang, X., Humphreys, W. M., Leclère, Q., Malgoezar, A., Michel, U., Padois, T., Pereira, A., Picard, C., Sarradj, E., Siller, H., Simons, D. G., Spehr, C., A review of acoustic imaging methods using phased microphone arrays. CEAS Aeronautical Journal, 10(1), 197-230 (2019). https://dx.doi.org/10.1007/s13272-019-00383-4

${ }^{7}$ Li, Y., Smith, M. G.; Zhang, X., Identification and attenuation of a tonal-noise source on an aircraft's landing gear, Journal of Aircraft, 47(3), 796-804, (2010). https://dx.doi.org/10.2514/1.43183

8 Fleury, V., Davy, R., Beamforming-based noise level measurements in hard-wall closed-section wind tunnels, 18th AIAA/CEAS Aeroacoustics Conference (33rd AIAA Aeroacoustics Conference), 2226, (2012). https://dx.doi.org/10.2514/6.2012-2226

9 Li, Y., Smith, M., Zhang, X., Measurement and control of aircraft landing gear broadband noise. Aerospace Science and Technology, 23(1), 213-223, (2012). https://dx.doi.org/10.1016/j.ast.2011.07.009 
${ }^{10}$ Chen, B., Wei, Q., Shao, T., Li, Y., Huang, X., Aeroacoustic imaging experiments of airframe noise in lined wall closed-section wind tunnel, Journal of Aerospace engineering, 28(4), 04014090, (2015). https://dx.doi.org/10.1061/(ASCE)AS.1943-5525.0000422

11 Al Tlua, B., Rocha, J., Development and Testing of an Aeroacoustic Wind Tunnel Test Section, Canadian Acoustics, 47(3), 64-65, (2019).

12 Merino-Martinez, R., van der Welden, W., Avallone, F., Ragni, D., Acoustic measurements of a DU96-W-180 airfoil with flow-misaligned serrations at a high Reynolds number in a closed-section wind tunnel, Proceedings of the 7th International Conference on Wind Turbine Noise: Rotterdam, (2017).

13 Brown, K., Devenport, W., Borgoltz, A., Exploitation of hybrid anechoic wind tunnels for aeroacoustic and aerodynamic measurements, CEAS Aeronautical Journal, 10(1), 251-266, (2019). https://dx.doi.org/10.1007/s13272019-00385-2

14 Devenport, W.J., Burdisso, R.A., Borgoltz, A., Ravetta, P.A., Barone, M.F., Brown, K.A., Morton, M.A.: The kevlar-walled anechoic wind tunnel, J. Sound Vib., 332(17), 3971-3991, (2013). https://dx.doi.org/10.1016/j.jsv.2013.02.043

15 Ito, T., Ura, H., Yokokawa, Y., Aeroacoustic noise measurements in aerodynamic low-speed wind tunnels, 26th International Congress of the Aeronautical Sciences, ICAS, p. 2008, (2008).

16 Jaeger, S., Horne, W., Allen, C., Effect of surface treatment on array microphone self-noise, 6th Aeroacoustics Conference and Exhibit. p. 1937, (2000). https://dx.doi.org/10.2514/6.2000-1937

17 Van Dercreek, C., Merino-Martinez, R., Sijtsma, P., Snellen, M., Evaluation of the effect of microphone cavity geometries on acoustic imaging in wind tunnels, Applied Acoustics, 181, 108154, (2021). https://dx.doi.org/10.1016/j.apacoust.2021.108154
${ }^{18}$ Sinnige, T., Della Corte, B., De Vries, R., Merino-Martinez, R., Ragni, D., Eitelberg, G., Veldhuis, L. M., Alleviation of propeller-slipstream-induced unsteady pylon loading by a flow-permeable leading edge. Journal of Aircraft, 56(3), 1214-1230, (2019). https://dx.doi.org/10.2514/1.C035250

${ }^{19}$ Santana, L. D., Catalano, F. M., Medeiros, M. A., and Carmo, M., The Update Process and Characterization of the Sao Paulo University Wind-Tunnel for Aeroacoustics Testing, 27th International Congress of the Aeronautical Sciences ICAS, Nice France, (2010).

20 Santana, L. D., Catalano, F., Medeiros, M., Carmo, M., The update of an aerodynamic wind-tunnel for aeroacoustics testing, Journal of Aerospace Technology and Management, 6(2), 111-118, (2014). https://dx.doi.org/10.5028/jatm.v6i2.308

${ }^{21}$ Catalano, F. M., The new closed circuit wind tunnel of the aircraft laboratory of university of Sao Paulo, 24th International Congress of the Aeronautical Sciences ICAS. Yokohama, Japan, (2004).

22 Soderman, P.T., Allen, C.S., Aeroacoustic measurements, Springer Science \& Business Media, New York, (2002).

${ }^{23}$ Fonseca, W. D., Ristow J. P., Sanches, D. G., Gerges, S., A different approach to archimedean spiral equation in the development of a high frequency array. SAE Technical Paper, No. 2010-36-0541 (2010). https://dx.doi.org/10.4271/201036-0541

${ }^{24}$ Künstner, R., Potthoff, J., Essers, U., The aero-acoustic wind tunnel of Stuttgart University, SAE transactions, pp. 1119-1135, (1995).

${ }^{25}$ Collar, A. R. Some experiments with cascades of aerofoils, A.R.C. Technical Report 1768, Aeronautical Research Committee, (1936).

${ }^{26}$ Giraldo, D.A., Experimental Aeroacoustic and Aerodynamic Analysis of a Large-scale Flap Side-edge Model, dissertation (Master of Science), graduate program in Mechanical Engineering, São Carlos School of Engineering, University of São Paulo, (2019).

${ }^{27}$ Sijtsma, P., Phased array beamforming applied to wind tunnel and fly-over tests, NLR-TP-2010-549 Report, (2010). 